\title{
Computed Tomography- and Radiography-Based Morphometric Analysis of the Lateral Mass of the Subaxial Cervical Spine in the Indian Population
}

\author{
Nirmal D Patil, Sudhir K Srivastava, Sunil Bhosale, Shaligram Purohit \\ Department of Orthopaedics, King Edward Memorial Hospital, Seth Gordhandas Sunderdas Medical College, Parel, Mumbai, India
}

Study Design: This was a double-blinded cross-sectional study, which obtained no financial support for the research.

Purpose: To obtain a detailed morphometry of the lateral mass of the subaxial cervical spine.

Overview of Literature: The literature offers little data on the dimensions of the lateral mass of the subaxial cervical spine.

Methods: We assessed axial, sagittal, and coronal computed tomography (CT) cuts and anteroposterior and lateral X-rays of the lateral mass of the subaxial cervical spine of 104 patients (2,080 lateral masses) who presented to a tertiary care public hospital (King Edward Memorial Hospital, Mumbai) in a metropolitan city in India.

Results: For a majority of the parameters, males and females significantly differed at all levels $(p<0.05)$. Females consistently required higher $(p<0.05)$ minimum lateral angulation and lateral angulation. While the minimum lateral angulation followed the order of $\mathrm{C} 5<\mathrm{C} 4<\mathrm{C} 6<\mathrm{C} 3$, the lateral angulation followed the order of $\mathrm{C} 3<\mathrm{C} 5<\mathrm{C} 4<\mathrm{C} 6$. The lateral mass becomes longer and narrower from $\mathrm{C} 3$ to C7. In axial cuts, the dimensions increased from C3 to C6. The sagittal cut thickness and diagonal length increased and the sagittal cut height decreased from C3 to C7. The sagittal cut height was consistently lower in the Indian population at all levels, especially at the C7 level, as compared with the Western population, thereby questioning the acceptance of a 3.5-mm lateral mass screw. A good correlation exists between $\mathrm{X}$-ray- and CT-based assessments of the lateral mass.

Conclusions: Larger lateral angulation is required for Indian patients, especially females. The screw length can be effectively calculated by analyzing the lateral X-ray. A CT scan should be reserved for specific indications, and a caution must be exercised while inserting $\mathrm{C} 7$ lateral mass screws.

Keywords: Cervical; Nerve; Computed tomography scan

\section{Introduction}

The cervical spine is a frequent site of traumatic fracture and dislocation, inflammatory diseases, tumors, and degenerative conditions. The treatment of these conditions aims at neurovascular decompression, anatomic reduc- tion, rigid internal fixation, solid fusion, and early rehabilitation. Surgical stabilization is required for immediate and long-term stability of the spine and neurovascular protection till fusion occurs. The result of several anatomic studies have demonstrated ethnic variations in the lateral mass dimensions between each vertebrae and con-

Received Oct 23, 2016; Revised May 3, 2017; Accepted May 21, 2017

Corresponding author: Nirmal D Patil

Department of Orthopaedics, King Edward Memorial Hospital, Seth Gordhandas Sunderdas Medical College, Acharya Donde Marg, Parel, Mumbai 400012, India

Tel: +91-8425892498, Fax: +91-22-410-7463, E-mail: nirmalpatil2008@gmail.com 
siderable variation in the lateral mass dimension between each cervical vertebrae [1-4]. No study has been conducted to quantify the lateral mass of the subaxial cervical spine in the Indian population. All assessments conducted till date are based on computed tomography (CT) scans, and no study has corroborated the CT- and X-ray-based findings.

\section{Materials and Methods}

The Institutional Review Board of Seth Gordhandas Sunderdas Medical College and King Edward Memorial Hospital approved the protocol followed in this study (approval no., EC/105/2015). Patients who provided informed consent were enrolled in this study. We studied $\mathrm{CT}$ and X-rays images of the cervical spine of 104 patients of Indian origin, who presented to King Edward Memo-

Table 1. Axial cuts

\begin{tabular}{|c|c|c|}
\hline Level & Geometry of cuts & Measurements taken \\
\hline C3-C7 & $\begin{array}{l}\text { Perpendicular to the plane of lateral mass at the level of } \\
\text { centre of pedicle }\end{array}$ & $\begin{array}{l}\text { 1. Medio-lateral (width) } \\
\text { 2. Antero-posterior (depth) (Fig. 1) }\end{array}$ \\
\hline C3-C7 & $\begin{array}{l}\text { Cut in a plane parallel to the superior articulating facet of } \\
\text { that vertebrae and passing through the centre of lateral } \\
\text { mass on the posterior cortex }\end{array}$ & $\begin{array}{l}\text { 1. Medio-lateral (width) } \\
\text { 2. Antero-posterior (depth) (Fig. 2) }\end{array}$ \\
\hline C3-C6 & $\begin{array}{l}\text { Cut in a plane parallel to the superior articulating facet of } \\
\text { that vertebrae and passing through the centre of lateral } \\
\text { mass on the posterior cortex }\end{array}$ & $\begin{array}{l}\text { 1. The minimum lateral angulation to avoid penetrating the foramen transver- } \\
\text { sarium (Fig. 3A) } \\
\text { 2. The lateral angulation of the lateral mass screw to exit at the anterolateral } \\
\text { corner of lateral mass (Fig. 3B) }\end{array}$ \\
\hline C3-C6 & $\begin{array}{l}\text { A plane parallel to the superior articulating facet of that } \\
\text { vertebrae and passing through a point } 2 \mathrm{~mm} \text { medial and } \\
\text { superior to the centre of lateral mass on the posterior } \\
\text { cortex }\end{array}$ & $\begin{array}{l}\text { 1. The minimum lateral angulation to avoid penetrating the foramen transver- } \\
\text { sarium } \\
\text { 2. The lateral angulation of the lateral mass screw to exit at the anterolateral } \\
\text { corner of lateral mass }\end{array}$ \\
\hline
\end{tabular}

Table 2. Sagittal cuts

\begin{tabular}{lll}
\multicolumn{1}{c}{ Cuts } & \multicolumn{1}{c}{ Measurements } \\
C3-C7 & Through the centre of lateral mass & $\begin{array}{l}\text { Thickness: dorsal to ventral cortex through the centre of lateral mass (Fig. 4A) } \\
\text { Height: cephalo-caudal distance through the centre of lateral mass (Fig. 4B) } \\
\text { Diagonal height: tip of superior articular facet to tip of Inferior articular facet (Fig. 4C) } \\
\text { Facet angularity (Fig. 4D) }\end{array}$ \\
\hline
\end{tabular}

Table 3. Coronal cuts

\begin{tabular}{lll} 
Level & \multicolumn{1}{c}{ Cuts } & Measurements \\
C3-C7 & Through the centre of lateral mass & $\begin{array}{l}\text { Cephalo caudal height passing through the centre of lateral mass in that cut (Fig. 5A) } \\
\text { Medio lateral distance passing through the centre of lateral mass in that cut (Fig. 5B) }\end{array}$ \\
\hline
\end{tabular}

Table 4. X-ray based dimensions

\begin{tabular}{|c|c|c|}
\hline Level & View & Measurements \\
\hline \multirow[t]{2}{*}{ C3-C7 } & Anteroposterior view & $\begin{array}{l}\text { 1. Cephalo caudal distance: from the apex of the convex border of superior articular process to apex of } \\
\text { convex border of inferior articulating facet } \\
\text { 2. Mediolateral distance: through the most constricted part of the lateral mass (Fig. 6A) }\end{array}$ \\
\hline & Lateral view & $\begin{array}{l}\text { 1. Height: cephalo-caudal distance through the centre of lateral mass (Fig. 6B) } \\
\text { 2. Width along the centre of lateral mass (Fig. 6C) } \\
\text { 3. Diagonal height: tip of superior articular facet to tip of inferior articular facet (Fig. 6D) }\end{array}$ \\
\hline
\end{tabular}


rial Hospital with head injury, for their lateral mass dimensions. The height, weight, and body mass index (BMI) of the patients were evaluated. CT scan was screened to exclude fractures, dislocations, tumorous lesions, infection, degenerative conditions, and previous surgery, which are likely to alter the dimensions of the lateral mass. X-ray of the cervical spine in anteroposterior (AP) and lateral views with a marker of known size was taken. The axial coronal and sagittal cuts of the lateral mass and AP and lateral X-ray views were analyzed for the dimensions of the lateral mass of the subaxial cervical spine with OsiriX (ver. 6.5.2, 32 bit; Pixmeo, Bernex, Switzerland). All assessments were conducted by authors who were doubleblinded (demography of patient, measurement calculated by other authors), and each author performed the assessment twice to reduce inter- and intraobserver variations

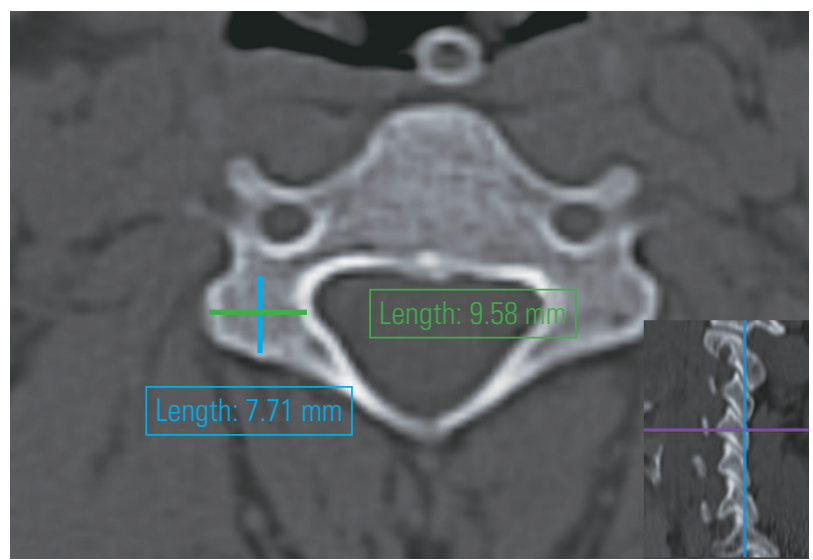

Fig. 1. Axial anteroposterior and mediolateral diameter measurement in a plane perpendicular to the posterior surface of the lateral mass (inset: the sagittal view showing the orientation of the axial cut).
(Tables 1-4, Figs. 1-6).

\section{Calculation of the minimum lateral angulation}

The minimum lateral angulation is calculated in a plane parallel to the superior articular facet (SAF) of that vertebrae and passing through a point $2 \mathrm{~mm}$ medial and superior to the center of the lateral mass on the posterior cortex (Fig. 7A).

\section{Center of the lateral mass}

The center of the lateral mass is calculated by drawing two lines, one tangent to the lateral-most extent of the lateral

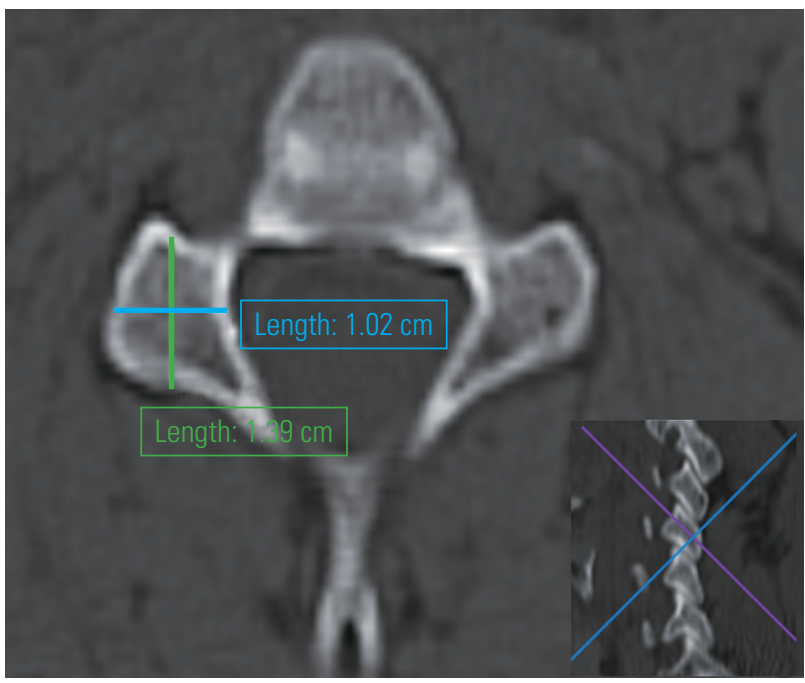

Fig. 2. Axial anteroposterior and mediolateral diameter measurement in a plane parallel to the superior articular facet (inset: the sagittal view showing the orientation of the axial cut).
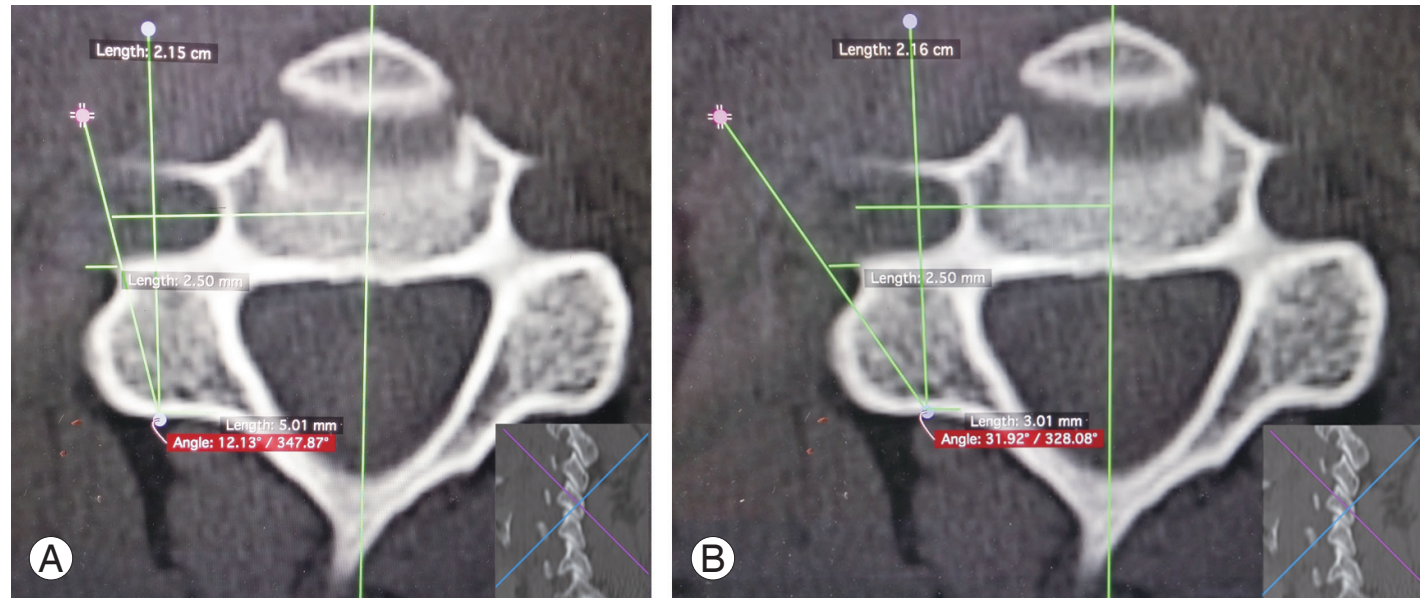

Fig. 3. (A) The measurement of the minimum lateral angulation (inset: the sagittal view showing the orientation of the axial cut). (B) The measurement of the lateral angulation (inset: the sagittal view showing the orientation of the axial cut). 
mass and another parallel to the first and passing through the valley of the junction of the lamina and lateral mass on the posterior surface. In between these lines lies the center of the lateral mass on the posterior surface.

\section{Point C}

This point is $2 \mathrm{~mm}$ medial to the center of the lateral mass on the posterior cortex in the axial cut in a plane $2 \mathrm{~mm}$ superior to the plane passing through the center of the lateral mass and parallel to SAF.

\section{Point D}

This point is located on a line parallel to the line bisecting the vertebral body and the canal and passing through
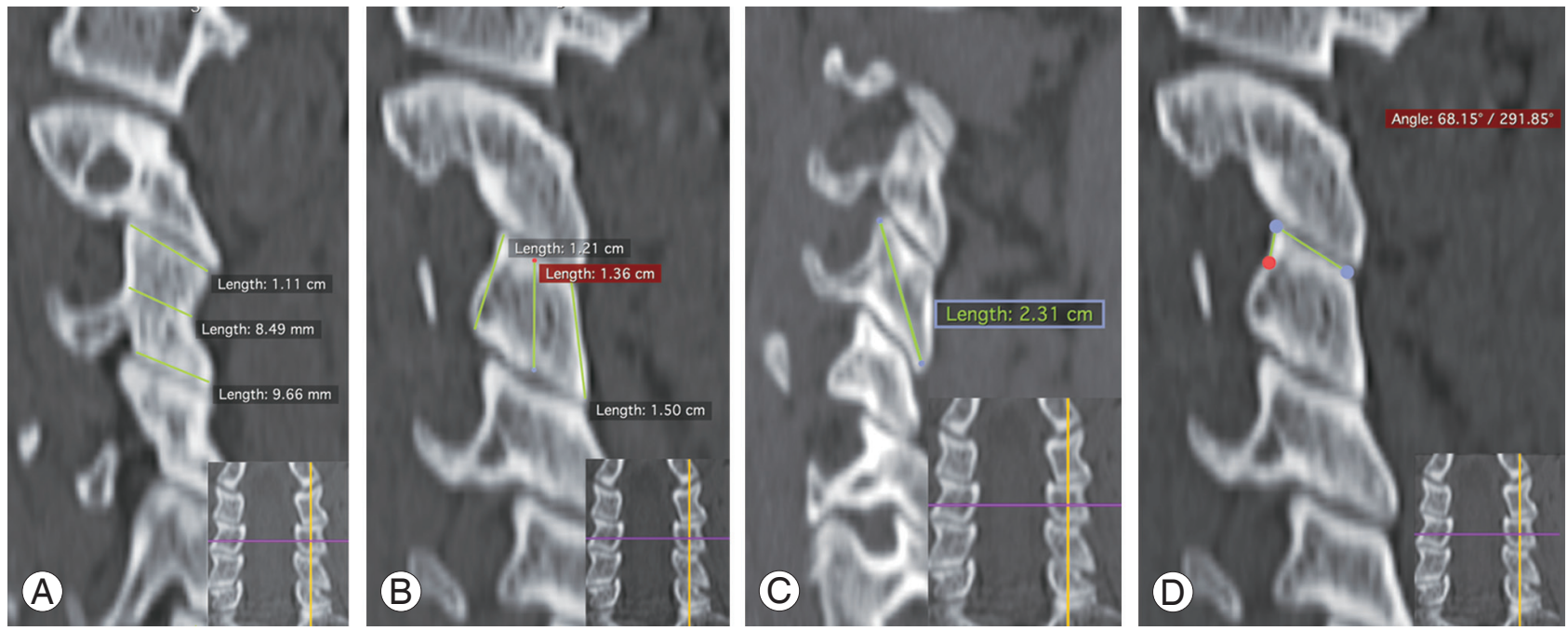

Fig. 4. (A) The measurement of the thickness of the lateral mass in a sagittal cut (inset: the coronal view showing the orientation of the sagittal cut through the center of the lateral mass). (B) The measurement of the height of the lateral mass in a sagittal cut (inset: the coronal view showing the orientation of the sagittal cut through the center of the lateral mass). (C) The measurement of the diagonal height of the lateral mass in a sagittal cut (inset: the coronal view showing the orientation of the sagittal cut through the center of the lateral mass). (D) The measurement of facet angularity in a sagittal cut (inset: the coronal view showing the orientation of the sagittal cut through the center of the lateral mass).
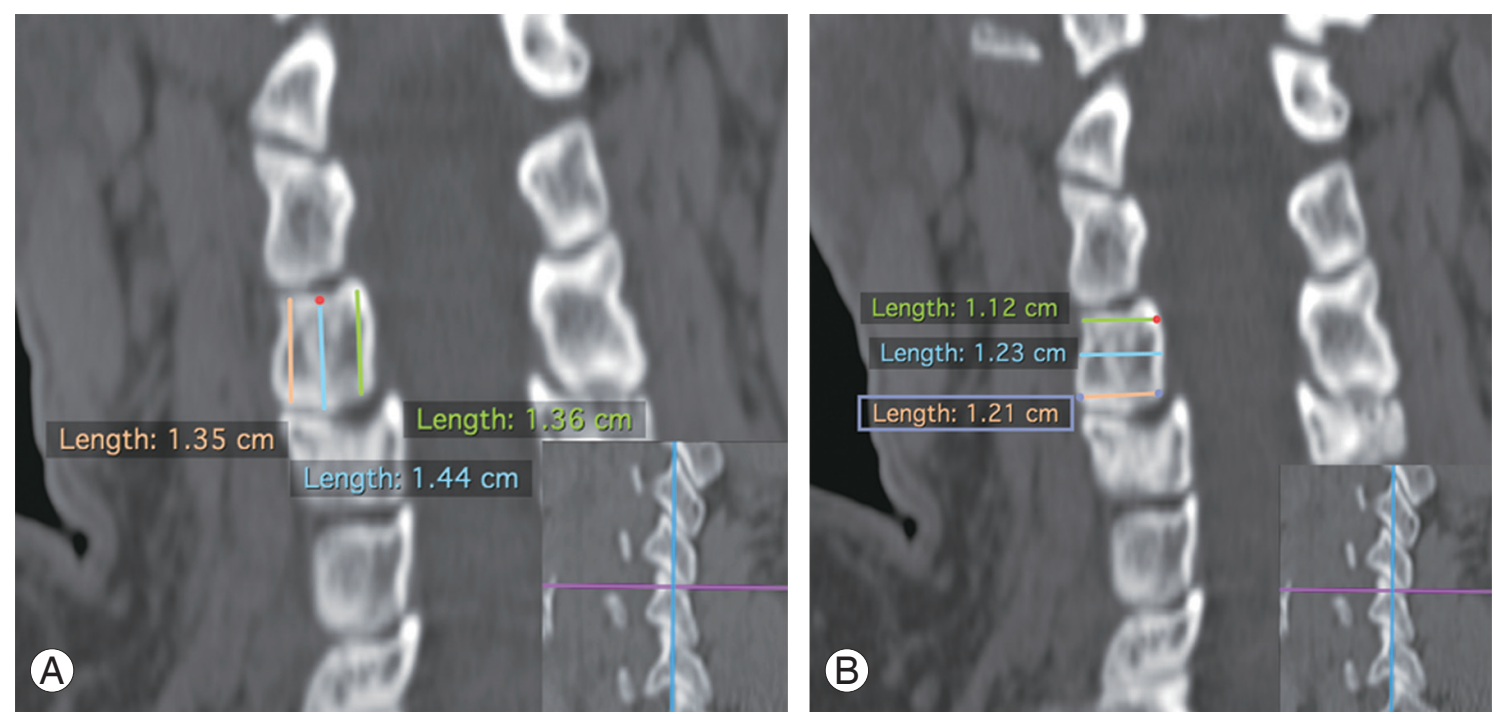

Fig. 5. (A) The measurement of the height of the lateral mass in a coronal cut (inset: the sagittal view showing the orientation of the coronal cut through the center of the lateral mass). (B) The measurement of the width of the lateral mass in a coronal cut (inset: the sagittal view showing the orientation of the coronal cut through the center of the lateral mass). 
point C.

\section{Calculation of point $E$}

In an axial cut perpendicular to the posterior surface of the lateral mass showing the full circle of the foramen transversarium, the distance between the lateral-most extent of the foramen transversarium and the central bisecting line is calculated (Fig. 7B). This value is extrapolated to the axial cut parallel to SAF, and $2.5 \mathrm{~mm}$ is added. This is different
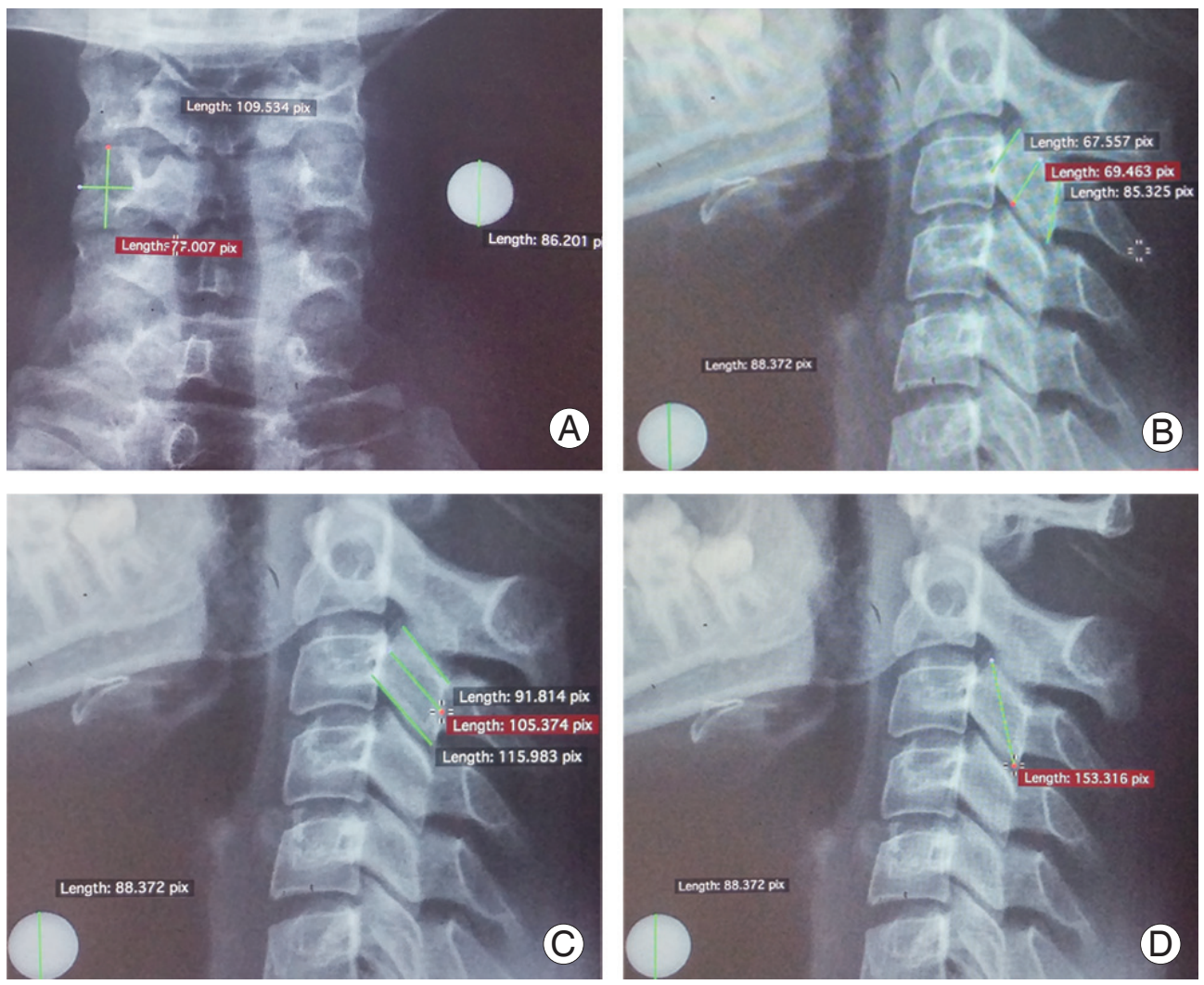

Fig. 6. (A) The measurement of the height and width of the lateral mass on anteroposterior $X$-ray of the cervical spine. (B) The measurement of the height of the lateral mass on lateral X-ray of the cervical spine. (C) The measurement of the width of the lateral mass on lateral X-ray of the cervical spine. (D) The measurement of the diagonal height of the lateral mass on lateral $X$-ray of the cervical spine.
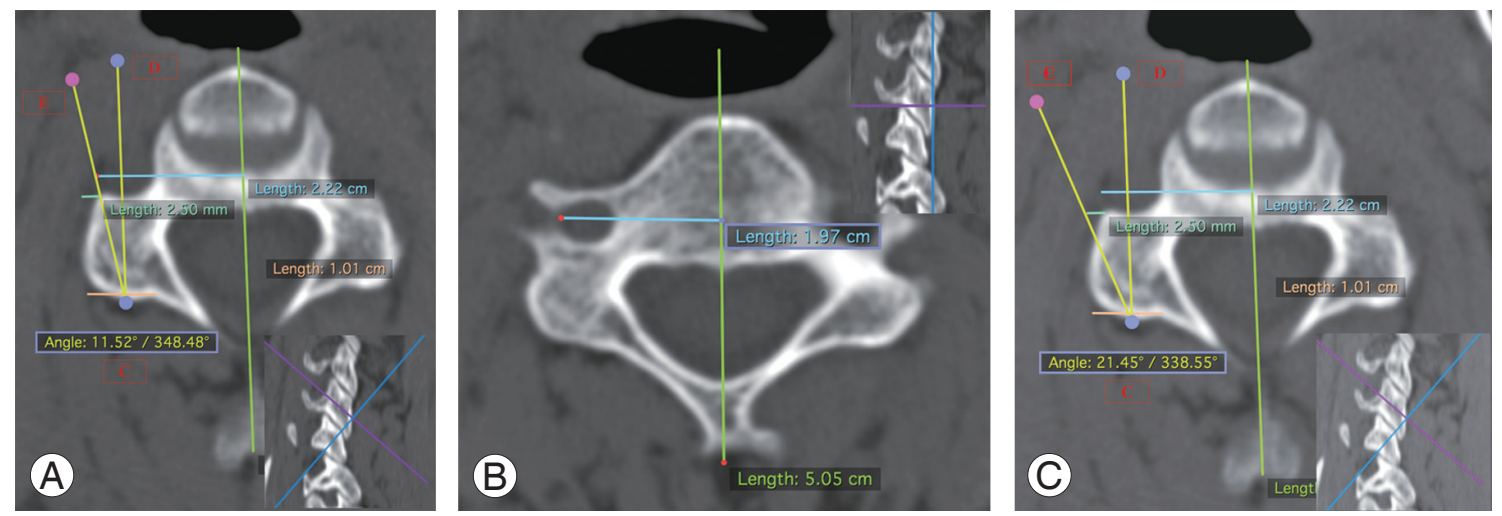

Fig. 7. (A) Calculation of the minimum lateral angulation angle DCE (inset: the sagittal view showing the orientation of the cut). (B) Calculation of the maximum distance of the lateral-most boundary of the foramen transversarium in a cut showing all the borders of the foramen (inset: showing the orientation of the cut on the sagittal view). (C) Calculation of the lateral angulation angle DCE (inset: the sagittal view showing the orientation of the cut). 

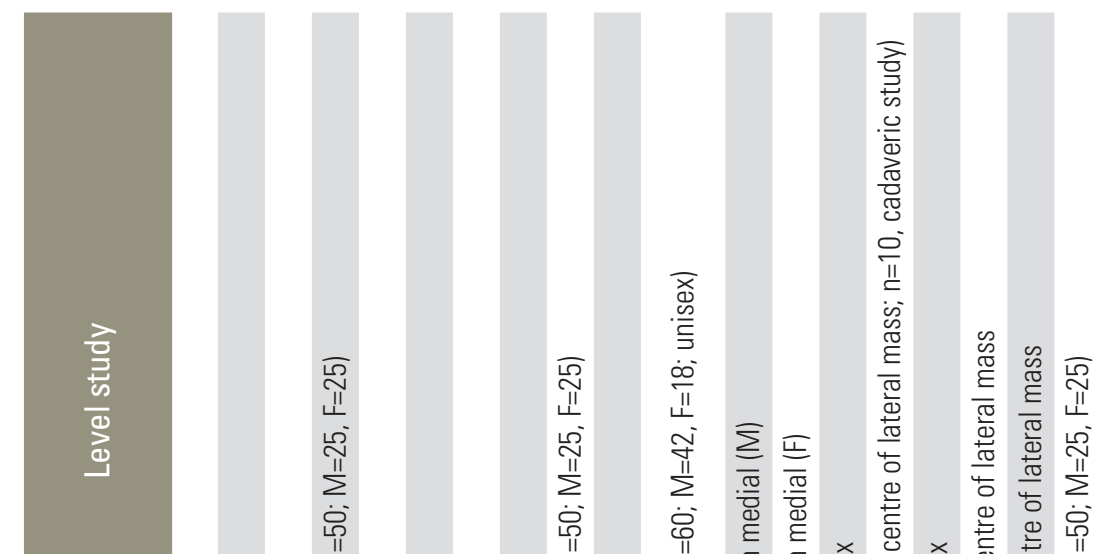

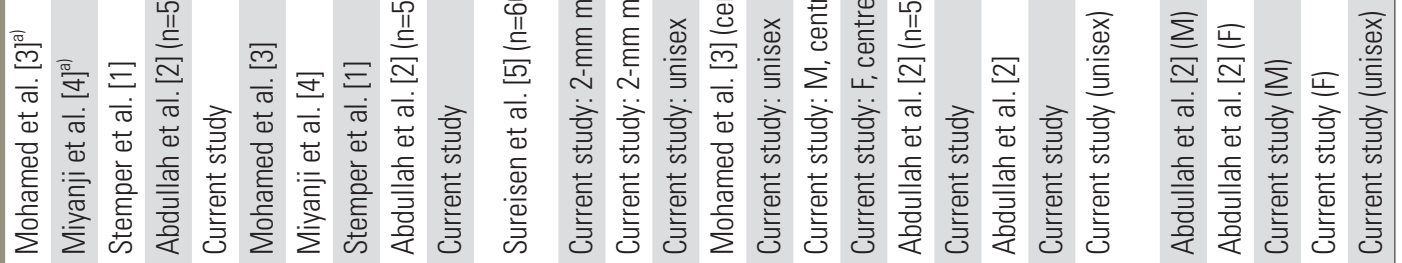

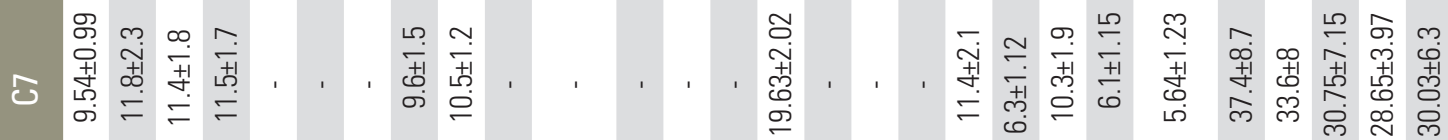

হ

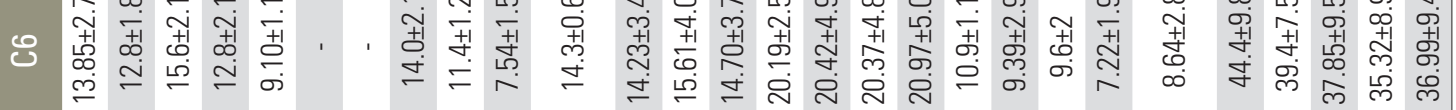

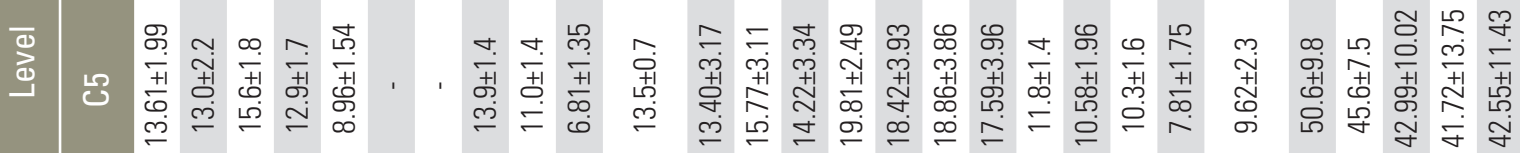

ه

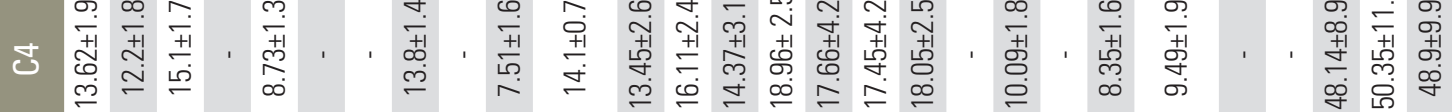

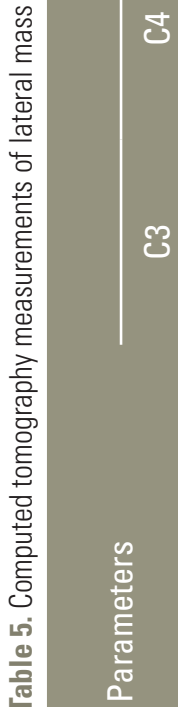

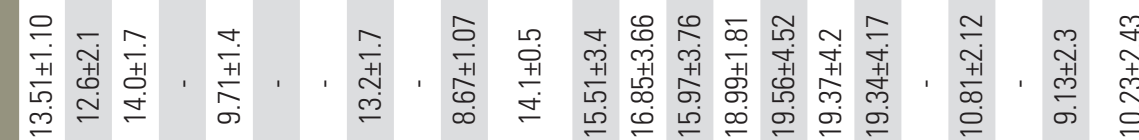

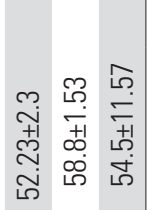

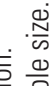

茎 恳

흔 흔
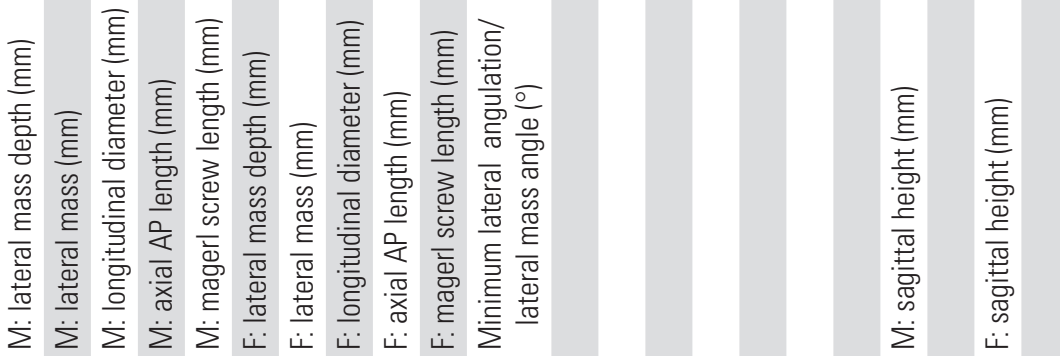

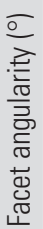

$\sqrt{\pi} \frac{1}{2}$

远安

ब

竞离竞

它

造离. 
from that reported by Sureisen et al. [5]. Angle DCE is the minimum lateral angulation of the lateral mass screw to avoid penetrating the lateral cortex of the foramen transversarium. (For a lateral mass screw of $3.5-\mathrm{mm}$ diameter, a minimum of $0.75 \mathrm{~mm}$ of hold is required for the screw. Therefore, the axis of the screw should be $2.5 \mathrm{~mm}$ lateral to the boundary of the foramen transversarium.)

\section{Calculation of lateral angulation}

It is calculated in a plane parallel to SAF of that vertebrae and passing through a point $2 \mathrm{~mm}$ medial and superior to the center of the lateral mass (Fig. 7C). Points C and D are similar to those reported earlier. Point $\mathrm{E}$ is located $2.5 \mathrm{~mm}$ lateral to the anterolateral corner of the lateral mass in the axial cut parallel to SAF.

The basis for calculation of lateral angulation is based on the study done by Pait et al. [6] studied the basis of the lateral angulation. In a transverse section through the upper portion of the superior articular process, the spinal nerve lies on the anteromedial surface of the lateral mass. As we move below, the spinal nerve courses to the anterolateral surface of the lateral mass [7-10]. Hence, screw directed superiorly and anterolaterally would avoid damaging the spinal nerve.

The data were analyzed with IBM SPSS ver. 22.0 (IBM Corp., Armonk, NY, USA). The unpaired $t$-test was used to compare the mean of each parameter. The results of this study were compared with those of other studies using the unpaired $t$-test. The Pearson's correlation matrix was used to establish the correlation between the X-ray- and CTbased findings.

\section{Results}

This study enrolled 104 patients with a mean age of 38.8 years (range, 18-75 years). Among these, 36 were female patients with a mean age of 44.28 years (range, 18-72 years), and 68 were male patients with a mean of 35.90 years (range, 18-75 years). A good inter-observer correlation existed in the measurements taken $(r=0.005)$. The mean weight was as follows: female patients, $45.4 \pm 3.8 \mathrm{~kg}$; male patients, $57.1 \pm 6.3 \mathrm{~kg}$; and entire sample, $50.85 \pm 4.2$ $\mathrm{kg}$. The mean height was as follows: female patients, $156.3 \pm 5.2 \mathrm{~cm}$; male patients, $165.2 \pm 6.3 \mathrm{~cm}$; and entire sample, $162.9 \pm 5.8 \mathrm{~cm}$. The mean BMI was as follows: female patients, $18.6 \mathrm{~kg} / \mathrm{m}^{2}$; male patients, $20.8 \mathrm{~kg} / \mathrm{m}^{2}$; and entire sample, $19.2 \mathrm{~kg} / \mathrm{m}^{2}$. No correlation was found between the anthropometric measurements and the lateral mass dimensions.

Refer to the Table 5 for the following.

(1) Axial cuts perpendicular to the plane of the lateral mass: the depth (Roy Camille screw length) was the highest at the $\mathrm{C} 3$ level and the lowest at the $\mathrm{C} 5$ level $(\mathrm{C} 5<\mathrm{C} 4<\mathrm{C} 6<\mathrm{C} 3)$. The width was the highest at the $\mathrm{C} 6$ level and the lowest at the $\mathrm{C} 4$ level $(\mathrm{C} 4<\mathrm{C} 3<\mathrm{C} 5<\mathrm{C} 6)$.

(2) Axial cut in a plane parallel to SAF of that vertebrae and passing through the center of the lateral mass on the posterior cortex: the depth (Magerl screw length) was the highest at the $\mathrm{C} 7$ level $(21.5 \mathrm{~mm})$ and the lowest at the $\mathrm{C} 5$ level $(13.1 \mathrm{~mm})(\mathrm{C} 5<\mathrm{C} 3<\mathrm{C} 4<\mathrm{C} 4<\mathrm{C} 7)$. The width was the highest at the $\mathrm{C} 7$ level $(12.9 \mathrm{~mm})$ and the lowest at the $\mathrm{C} 3$ level $(11 \mathrm{~mm})(\mathrm{C} 3<\mathrm{C} 5<\mathrm{C} 4<\mathrm{C} 6<\mathrm{C} 7)$.

Females had a higher minimum lateral and lateral angulation at all levels.

(3) The minimum lateral angulation followed the order of $\mathrm{C} 5\left(14.22^{\circ}\right)<\mathrm{C} 4<\mathrm{C} 6<\mathrm{C} 3\left(15.97^{\circ}\right)$ (Fig. 8).

(4) The lateral angulation was the highest at the C6 level $\left(24.41^{\circ}\right)$ and the lowest at the C3 level $\left(22.70^{\circ}\right)$ $(\mathrm{C} 3<\mathrm{C} 5<\mathrm{C} 4<\mathrm{C} 6)$.

(5) The sagittal thickness was the highest at the C7 level $(18 \mathrm{~mm})$ and the lowest at the C3 level $(12.4 \mathrm{~mm})$ $(\mathrm{C} 5<\mathrm{C} 4<\mathrm{C} 3<\mathrm{C} 6<\mathrm{C} 7)$.

(6) The diagonal height was the highest at the $\mathrm{C} 7$ level $(22.8 \mathrm{~mm})$ and the lowest at the C4 level $(19.91 \mathrm{~mm})$ $(\mathrm{C} 4<\mathrm{C} 5<\mathrm{C} 3<\mathrm{C} 6<\mathrm{C} 7)$.

(7) The coronal height was the highest at the C3 level $(12.9 \mathrm{~mm})$ and the lowest at the C5 level $(10.1 \mathrm{~mm})$ $(\mathrm{C} 5<\mathrm{C} 7<\mathrm{C} 6<\mathrm{C} 4<\mathrm{C} 3)$.

(8) The coronal width was the highest at the C7 level $(12.4 \mathrm{~mm})$ and the lowest at the $\mathrm{C} 4$ level $(10.4 \mathrm{~mm})$ $(\mathrm{C} 4<\mathrm{C} 3<\mathrm{C} 5<\mathrm{C} 6<\mathrm{C} 7)$.

A two-tailed $t$-test was used to calculate the difference between the means (Table 6).

The X-ray-based dimensions were as follows.

(1) AP view: The cephalocaudal distance was the highest at the $\mathrm{C} 3$ level $(7.55 \mathrm{~mm})$ and the lowest at the $\mathrm{C} 5$ level $(7.15 \mathrm{~mm})(\mathrm{C} 5<\mathrm{C} 4<\mathrm{C} 6<\mathrm{C} 7<\mathrm{C} 3)$. The mediolateral distance was the highest at the $\mathrm{C} 7$ level $(9.2 \mathrm{~mm})$ and the lowest at the $\mathrm{C} 3$ level $(7.55 \mathrm{~mm})(\mathrm{C} 3<\mathrm{C} 4<\mathrm{C} 6<\mathrm{C} 5<\mathrm{C} 7)$.

(2) Lateral view: The height was the highest at the $\mathrm{C} 3$ level $(8.2 \mathrm{~mm})$ and the lowest at the $\mathrm{C} 7$ level $(6.0 \mathrm{~mm})$ $(\mathrm{C} 7<\mathrm{C} 6<\mathrm{C} 5<\mathrm{C} 4<\mathrm{C} 3)$. The width was the highest at the C7 level $(16.8 \mathrm{~mm})$ and the lowest at the C4 level (12.6 


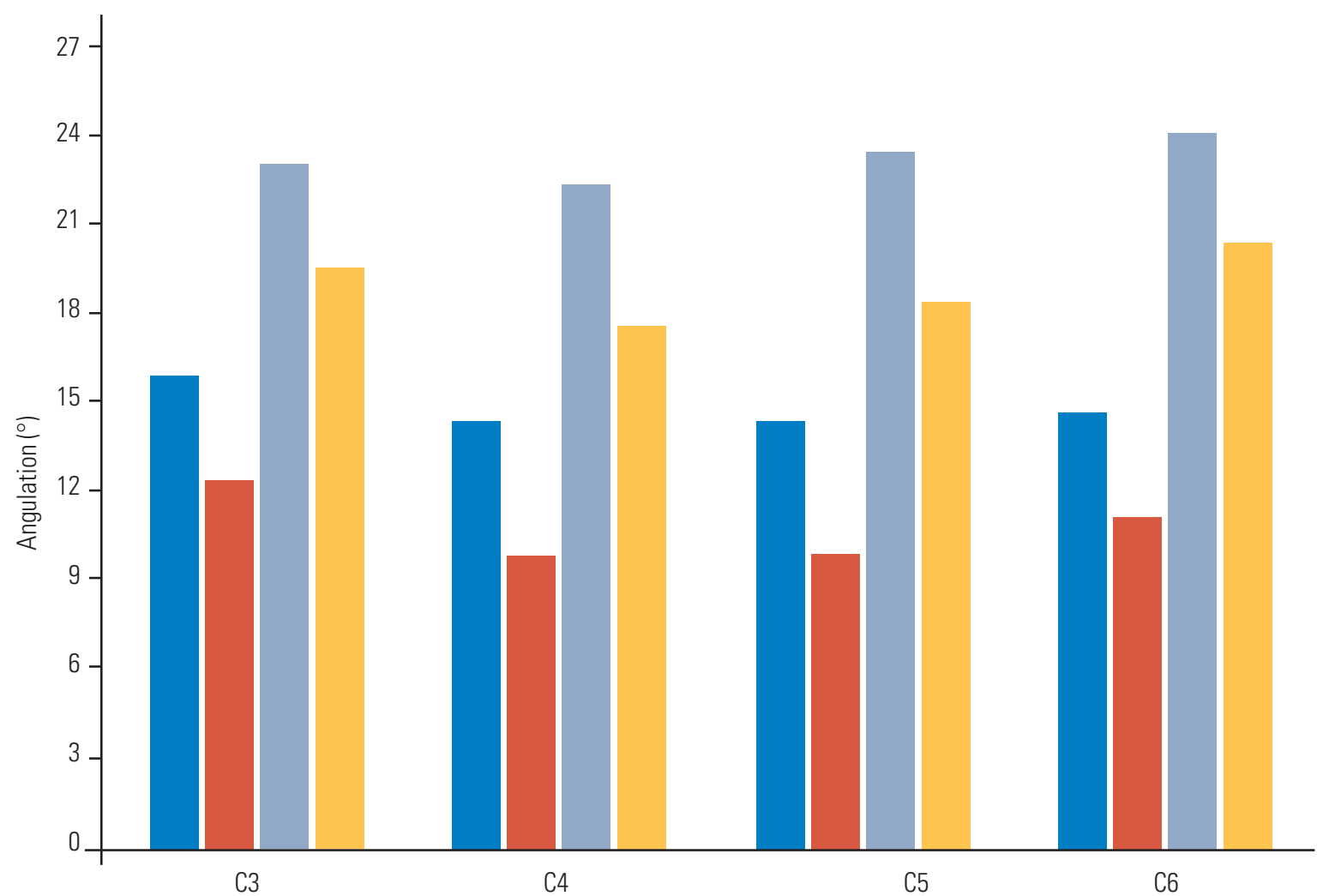

Axial cut minimum lateral angulation: a plane parallel to the superior articulating facet of that vertebrae and passing through a point $2 \mathrm{~mm}$ medial and superior to the centre of lateral mass on the posterior cortex.

Axial cut minimum lateral angulation: a plane parallel to the superior articulating facet of that vertebrae and passing through the centre of lateral mass on the posterior cortex.

Axial cut lateral angulation: a plane parallel to the superior articulating facet of that vertebrae and passing through a point $2 \mathrm{~mm}$ medial and superior to the centre of lateral mass on the posterior cortex.

Axial cut lateral angulation: a plane parallel to the superior articulating facet of that vertebrae and passing through the centre of lateral mass on the posterior cortex.

Fig. 8. Comparison of the minimum lateral angulation and the lateral angulation at cervical levels (C3-C6).

Table 6. $p$-vaule of 2 tailed $t$-test and signficance of the difference between the means

\begin{tabular}{|c|c|c|c|c|c|c|c|c|}
\hline \multirow[t]{2}{*}{$\begin{array}{l}\text { Vertebrae } \\
\text { level }\end{array}$} & \multirow[t]{2}{*}{$\begin{array}{l}\text { Minimum lateral } \\
\text { angulation } \\
\text { (Sureisen et al. [5]) }\end{array}$} & \multirow[t]{2}{*}{$\begin{array}{l}\text { Lateral angulation } \\
\text { (Mohamed et al. [3]) }\end{array}$} & \multicolumn{2}{|c|}{$\begin{array}{c}\text { Saggital height } \\
\text { (Abdullah et al. [2]) }\end{array}$} & \multicolumn{2}{|c|}{$\begin{array}{l}\text { Facet angularity } \\
\text { (Abdullah et al. [2]) }\end{array}$} & \multicolumn{2}{|c|}{$\begin{array}{c}\text { Axial anteroposterior } \\
\text { diameter } \\
\text { (Abdullah et al. [2]) }\end{array}$} \\
\hline & & & M & $\mathrm{F}$ & $\mathrm{M}$ & $\mathrm{F}$ & $\mathrm{M}$ & $\mathrm{F}$ \\
\hline C3 & 0.0002 (S) & 0.69 (NS) & & & & & & \\
\hline C4 & 0.5 (NS) & 0.34 (NS) & & & & & & \\
\hline C5 & 0.105 (NS) & 0.2759 (NS) & $0.05(S)$ & 0.001 (S) & 0.0015 (S) & 0.24 (NS) & 0.0001 (S) & 0.0001 (S) \\
\hline C6 & 0.411 (NS) & 0.8848 (NS) & 0.0013 (S) & 0.001 (S) & 0.00245 (S) & 0.066 (NS) & 0.0001 (S) & 0.0001 (S) \\
\hline $\mathrm{C7}$ & & & $0.0001(S)$ & 0.0001 (S) & 0.0003 (S) & 0.002 (S) & & \\
\hline
\end{tabular}

$p$-value of 2 tailed $t$-test and the significance of the difference between the means.

$M$, male; F, female; S, significant; NS, not significant.

$\mathrm{mm})(\mathrm{C} 4<\mathrm{C} 3<\mathrm{C} 5<\mathrm{C} 6<\mathrm{C} 7)$. The diagonal length was the highest at the $\mathrm{C} 7$ level $(22.67 \mathrm{~mm})$ and the lowest at the
C3 level $(19.25 \mathrm{~mm})(\mathrm{C} 3<\mathrm{C} 4<\mathrm{C} 5<\mathrm{C} 6<\mathrm{C} 7)$.

The Pearson's correlation matrix identified a significant 
correlation between the X-ray- and CT-based parameters $(r=0.001)$ : (1) AP view: the cephalocaudal distance and CT sagittal cut height; the mediolateral distance and CT coronal cut width; (2) lateral view: the height and CT sagittal cut height; the width and CT sagittal cut thickness; the diagonal height and CT diagonal height $(r \leq 0.01)$.

No significant correlation was found between (1) the AP view cephalocaudal distance and CT coronal cut height $(r=0.896)$ and (2) the lateral view height and CT coronal cut cephalocaudal distance through the center of the lateral mass $(r=0.575)$. No statistically significant difference was observed between the right and left at all levels. The value for male patients versus female patients significantly differed at a majority of levels. Females, in general, had a lower value than males.

\section{Discussion}

No significant differences were observed in the lateral mass width dimensions between the Indian and Western population. The lateral mass AP diameter in this study can be compared only with that reported by Abdullah et al. [2] because of the variability in the definition of the anterior extent of the lateral mass used for the assessment in other studies [1-4]. Apparently, the lateral mass AP diameter in the Indian population is significantly lower than that in the Western population as reported by Abdullah (Tables 5, 6). The degenerative osteophyte formation/bony remodeling related to old age could have resulted in higher measurements in the study by Abdullah et al. [2] (54 years as compared to 38.8 years in our study).

In the axial cuts perpendicular to the plane of the lateral mass, the C3 lateral mass is oriented horizontally. The lateral masses get vertically inclined gradually as we move below. The $\mathrm{C} 7$ lateral mass is oriented roughly vertically.

The Indian population consistently presents a larger minimum lateral angulation (females $>$ males) compared with the Western population. While Sureisen et al. [5] reported the least angulation at $\mathrm{C} 5$ and the highest at $\mathrm{C} 6$, we found the least angulation at $\mathrm{C} 5$ and the highest at $\mathrm{C} 3$, followed by C6. The increased minimum lateral angulation below is because of the relative lateral position of the foramen transversarium with respect to the center of the vertebrae as we go further down the cervical vertebrae. The distance of the foramen transversarium from the center increases from C3 to C7 level, which is in accordance with that reported by Peng et al. [11], who suggested a $4^{\circ}$ medial angulation of the vertebral artery from C7 to C3. However, the higher angulation at the $\mathrm{C} 3$ level can be explained by a relatively smaller canal diameter with respect to the remaining vertebrae, resulting in more medial placement of the lateral mass relative to foramen transversarium [4]. For practical purposes, it is still less than the lateral angulation recommended by the Magerl technique $\left(25^{\circ}\right)$, which explains the low risk of vertebral artery injury. In cadaveric studies, the overall risk of vertebral artery injury is $4.7 \%$ [12-14]. In the study conducted by Pal et al. [15], even experienced spine surgeons could not aim for a predefined angulation, which could be because of human error and position of the neck (flexion or extension). However, on introducing an anatomical parameter, the accuracy improved [16]. In our institute, we first burr out all the osteophyte to visualize the boundaries of the lateral mass (a surgeon puts the periosteum deep to feel the boundaries of the lateral mass) and check the orientation of SAF before defining the angulation. Perhaps, this could help to bring down the risk of vertebral artery injury further. To date, we have not encountered any case of vertebral artery injury using the Magerl technique.

The lateral angulation increases as we move down the column, which is similar to that reported by Mohamed et al. [3]. The higher lateral angulation at C6 can be explained because of the extension of the anterolateral corner of the lateral mass at the C6 level. Apparently, the average lateral angulation at each level is between $23^{\circ}$ and $25^{\circ}$. Therefore, the margin of safety to avoid damaging the spinal nerves is meager with the Magerl technique. Because the mean lateral angulation at the $\mathrm{C} 6$ level is $24.4^{\circ}$ (margin of safety $=0.6^{\circ}$ ), it poses a higher risk of nerve root violation. The risk of nerve root injury is 5.2\% for the Roy-Camille technique and 22.6\% for the Magerl technique [12-14]. In the axial cut in a plane parallel to SAF and passing through the center, the anterolateral corner extends beyond its lateral cortex at the lower cervical levels. Hence, a screw directed toward the anterolateral corner skirts along the lateral cortex, particularly in the lower cervical levels, which can compromise the hold of the screw. Thus, the screw should not be directed toward the anterolateral corner at lower levels. A higher angulation to avoid the spinal nerve damage is recommended only at higher vertebral levels. The $\mathrm{C} 7$ height is $0.61 \mathrm{~cm}$, with no significant difference between males and females. Only $37 \%$ of males and $14.89 \%$ of females have their sagittal height dimensions above $5 \mathrm{~mm}$. Thus, a $3.5-\mathrm{mm}$ screw 
inserted at an angle more or less than the orientation angle of the lateral mass has a high chance of violating the facets. The Indian lateral mass appears to be significantly smaller at all levels ( $p=0.05-0.0001)$, especially at the C7 level $(p=0.0001)$, in comparison to the Western population, thereby necessitating a smaller diameter screw and careful selection of patients for C7 lateral mass screw placement. The axial AP diameter at $\mathrm{C} 5$ and $\mathrm{C} 6$ levels and the sagittal measurements at the $\mathrm{C} 7$ level are significantly different from those reported in Western studies $(p<0.05)$ (Table 6).

Facet angularity decreases by more than $6^{\circ}$ at each level and is least at $\mathrm{C} 7\left(30.66^{\circ}\right)$, which implies a higher superior angulation for the lateral mass screw in Indians with the steepest angulation at the $\mathrm{C} 7$ level. This highlights that a fixed cranial angulation of a lateral mass screw should not be used for every level. The cranial angulation should be determined from the orientation of SAF, which will ensure proper screw placement.

Seemingly, the coronal width and height and diagonal length do differ between the Indian and Western population. In a sagittal cut at the C3 level, the lateral mass is shaped like a boot. As the cut goes further laterally, its shape changes to a vertical parallelogram, and it becomes progressively thinner until it becomes diamond-shaped at the $\mathrm{C} 7$ level. The higher coronal dimensions at $\mathrm{C} 7$ are because the measurement is taken along the surface of $\mathrm{C} 7$ vertebrae and the relatively slanted orientation of the $\mathrm{C} 7$ lateral mass with respect to the horizontal. The $\mathrm{C} 7$ lateral mass is a long, thin, and broad diamond-shaped structure oriented at a steep angle to the horizontal. The sagittal cut height is the lowest at the $\mathrm{C} 7$ level (thin), the sagittal cut thickness is the highest at the $\mathrm{C} 7$ level (long), and coronal cut mediolateral distance is the highest at the $\mathrm{C} 7$ level (broad). The steep angulation makes the inferior part of the lateral mass a very thin structure, which explains the frequent complication of $\mathrm{C} 7-\mathrm{T} 1$ facet joint violation with a C7 lateral mass screw. These findings corroborate the results of Abdullah et al. [2]. Nonetheless, further studies are required to find the ideal trajectory for a C7 lateral mass screw.

To date, no study has compared the X-ray-based lateral mass dimensions and CT-based lateral mass dimensions. As a good correlation between $(r<0.001)$ lateral X-ray and sagittal CT measurement of the lateral mass of the cervical spine was found, a well-projected lateral X-ray with a marker is sufficient for selecting a safe screw length. A
CT scan should be reserved for other well-defined indications.

\section{Conclusions}

A significant difference was observed between the lateral mass of the Indian and Western population. Larger lateral angulation is required for Indian patients, especially females. In addition, anatomical landmarks for lateral angulation are necessary to avoid the subjective error of lateral angulation, which results in spinal nerve damage. A steeper trajectory of the screw is required for Indians as compared with the Western population. The screw length can be effectively calculated by analyzing the lateral X-ray. If the $\mathrm{C} 7$ lateral mass screw is to be inserted, a preoperative CT scan is advised to assess its sagittal height and facet angularity. A C7 pedicle screw must be used if the dimensions are lower than $5 \mathrm{~mm}$.

Take-home messages are as follow. (1) Larger lateral angulation is required for Indian patients, especially females. (2) The screw length can be effectively calculated by analyzing the lateral X-ray. A CT scan should be reserved for conditions affecting the anatomy of the lateral mass. (3) Caution must be exercised while inserting C7 lateral mass screws.

\section{Conflict of Interest}

No potential conflict of interest relevant to this article was reported.

\section{References}

1. Stemper BD, Marawar SV, Yoganandan N, Shender BS, Rao RD. Quantitative anatomy of subaxial cervical lateral mass: an analysis of safe screw lengths for Roy-Camille and magerl techniques. Spine (Phila Pa 1976) 2008;33:893-7.

2. Abdullah KG, Steinmetz MP, Mroz TE. Morphometric and volumetric analysis of the lateral masses of the lower cervical spine. Spine (Phila Pa 1976) 2009;34:1476-9.

3. Mohamed E, Ihab Z, Moaz A, Ayman N, Haitham AE. Lateral mass fixation in subaxial cervical spine: anatomic review. Global Spine J 2012;2:39-46.

4. Miyanji F, Mahar A, Oka R, Newton P. Biomechanical differences between transfacet and lateral mass screw-rod constructs for multilevel posterior 
cervical spine stabilization. Spine (Phila Pa 1976) 2008;33:E865-9.

5. Sureisen M, Saw LB, Wei Chan CY, Singh DA, Kwan MK. Radiological assessment of cervical lateral mass screw angulations in Asian patients. Indian J Orthop 2011;45:504-7.

6. Pait TG, McAllister PV, Kaufman HH. Quadrant anatomy of the articular pillars (lateral cervical mass) of the cervical spine. J Neurosurg 1995;82:1011-4.

7. Xu R, Ebraheim NA, Nadaud MC, Yeasting RA, Stanescu S. The location of the cervical nerve roots on the posterior aspect of the cervical spine. Spine (Phila Pa 1976) 1995;20:2267-71.

8. Ebraheim NA, Haman ST, Xu R, Yeasting RA. The anatomic location of the dorsal ramus of the cervical nerve and its relation to the superior articular process of the lateral mass. Spine (Phila Pa 1976) 1998;23:1968-71.

9. Ebraheim NA, Xu R, Challgren E. Radiologic evaluation of the relation of the screw tip to the nerve root in the intervertebral foramen. J Spinal Disord 1997;10:234-9.

10. Xu R, Haman SP, Ebraheim NA, Yeasting RA. The anatomic relation of lateral mass screws to the spinal nerves. A comparison of the Magerl, Anderson, and An techniques. Spine (Phila Pa 1976) 1999;24:205761.
11. Peng CW, Chou BT, Bendo JA, Spivak JM. Vertebral artery injury in cervical spine surgery: anatomical considerations, management, and preventive measures. Spine J 2009;9:70-6.

12. Barrey C, Mertens P, Jund J, Cotton F, Perrin G. Quantitative anatomic evaluation of cervical lateral mass xation with a comparison of the Roy-Camille and the Magerl screw techniques. Spine (Phila Pa 1976) 2005;30:E140-7.

13. Heller JG, Carlson GD, Abitbol JJ, Garfin SR. Anatomic comparison of the Roy-Camille and Magerl techniques for screw placement in the lower cervical spine. Spine (Phila Pa 1976) 1991;16(10 Suppl):S552-7.

14. Graham AW, Swank ML, Kinard RE, Lowery GL, Dials BE. Posterior cervical arthrodesis and stabilization with a lateral mass plate. Clinical and computed tomographic evaluation of lateral mass screw placement and associated complications. Spine (Phila Pa 1976) $1996 ; 21: 323-8$.

15. Pal D, Bayley E, Magaji SA, Boszczyk BM. Freehand determination of the trajectory angle for cervical lateral mass screws: how accurate is it? Eur Spine J 2011;20:972-6.

16. Bayley E, Zia Z, Kerslake R, Klezl Z, Boszczyk BM. Lamina-guided lateral mass screw placement in the sub-axial cervical spine. Eur Spine J 2010;19:660-4. 